\title{
Determination of Niobium and Tantalum in Geological Samples by ICP-AES After Preconcentration by Solid Phase Extraction on Activated Carbon or Chitin
}

\author{
*V. Padmasubashini and D.S.R. Murty \\ Atomic Minerals Directorate for Exploration and Research, Department of Atomic Energy \\ Begumpet, Hyderabad-500629, India
}

\section{INTRODUCTION}

Niobium $(\mathrm{Nb})$ [earlier

Columbium] and tantalum (Ta) are known as the "earth acid" elements because of the slightly acidic nature of their pentoxides. These elements are widely distributed in rocks and have never been found to occur as native metals $(1,2,3)$. Niobium and tantalum compounds are used in several high technology fields, such as the aerospace, nuclear and electronic industries and in the manufacturing of superconductors, cutting tools, thermocouples, dielectrics, cryotrons and superalloys $(2,3,4)$.

Because of its low thermal neutron capture cross- section, niobium finds use as a construction material in nuclear technology (4). It finds application as an end-plug in fuel elements in nuclear reactors and as protective covering (cladding) for uranium fuel elements in fast neutron and thermal neutron reactors. Tantalum is used as a construction material, particularly in vessels for chemical treatment of nuclear fuel. Further, Nb-Ta along with Zr-Hf forms two pairs of "twin" elements which are known as "high field strength elements". They are used as tools for the study of geochemical processes in the earth's mantle, thereby necessitating their precise determination at extremely low concentrations in mantle rocks (5).

Due to the above-mentioned applications, development of precise and accurate, as well as selec-

\footnotetext{
*Corressponding autbors:

${ }^{a}$ E-mail: padmasubasbini.amd@gov.in padmasubashini@gmail.com
}

\section{ABSTRACT}

Niobium and tantalum at low levels in geological samples have been determined by ICP-AES after preconcentration/separation by solid phase extraction using activated carbon or chitin as sorbents. Systematic investigations were carried out on the effect of various parameters on the sorption of niobium and tantalum on activated carbon and also on chitin and their quantitative desorption/ recovery. Investigations were also carried out on interferences from other concomitant ions in the sorption process. Accuracy of the method was ascertained by applying it to certified reference materials. The method was then applied to selected rock samples and relative standard deviation (RSD) values ranging from 1.0 to $6.0 \%$ were obtained. The values obtained were in good agreement with those obtained by other techniques.

The method is simple, accurate, selective and eco-friendly as non-toxic/bio-compatible sorbents have been employed. The present method also leads to a significant reduction in the amount of total dissolved salts present in the sample solution arising from the fusion flux and the matrix for aspiration into the plasma.
\end{abstract}

tive and sensitive analytical methods for the determination of $\mathrm{Nb}$ and Ta in diverse matrices (like high purity materials, industrial and geological samples) has always been deemed very important by analysts. Analytical methodologies by wet procedures are particularly difficult for $\mathrm{Nb}-\mathrm{Ta}$ since they exhibit similar physicochemical characteristics, their minerals are highly complex in composition, and hence their analysis requires a large number of separations to be performed, leading to material losses $(2,3,6)$. Further, $\mathrm{Nb}$ and $\mathrm{Ta}$ do not form simple soluble compounds in aqueous solutions. In neutral and acid solutions, they are hydrolyzed with the formation of hydrophyllic colloidal systems. In fact, hydrolysis in mineral acids results in a quantitative separation of $\mathrm{Nb}$ and $\mathrm{Ta}$ from many accompanying elements. Tartaric acid, oxalic acid, citric acid, fluoride and mixture of hydrogen peroxide and sulphuric acid are used to prevent hydrolysis. In most rock samples, the levels of niobium and tantalum are low, at ppm levels for niobium and at sub-ppm levels for tantalum. Therefore, one has to resort to highly sensitive techniques for the determination of these elements. ICP spectrometry (ICP-AES and ICP-MS) has emerged as the most advantageous and widely applied technique for the determination of these elements. Even with ICP spectrometry, direct determination of $\mathrm{Nb}$ and $\mathrm{Ta}$ in complex media such as geological materials is extremely difficult because of their low concentrations and the high levels of concomitant elements arising from the matrix and flux used which leads to various interferences and also blockage of instrumental components like cones, nebulizers etc. Hence, preconcentration/separation stages such as ion exchange, precipitation, co-precipitation, liquid-liquid extraction and solid phase extraction are usually employed prior to the determination of these elements at trace and 
ultra-trace levels in complex matrices so that the sensitivity and selectivity can be improved and the levels of total dissolved salts reduced.

For niobium-tantalum determination in geological samples, potassium bisulphate fusion followed by dissolution of the fused melt in tartaric acid solution is widely used. Lithium meta-borate fusions have also been reported $(2,3,6,7)$. Evaluation of various sample preparation techniques for the determination of $\mathrm{Nb}$ and Ta by ICP-MS in geological materials has also been carried out $(8,9,10)$. Hall and Pelchat have analyzed standard reference materials for $\mathrm{Nb}$, Ta, along with $\mathrm{Zr}$ and $\mathrm{Hf}$ after lithium meta-borate fusion and cupferron separation (11). Preconcentration/separation steps like precipitation, extraction chromatography, etc., have been employed prior to the determination of these elements by ICP-AES and ICP-MS $(12,13)$. Satyanarayana et al. (14) have employed acid hydrolysis separation for their estimation in niobate-tantalate and tin slag samples by ICP-AES.

Solid phase extraction is advantageous over other preconcentration methods because high enrichment factors are achievable and the methodology involved is simple (15). A variety of solid phase adsorbents like activated alumina, zeolites, silica gel, polyurethane foams, sawdust, yeast have been utilized, especially in the area of wastewater treatment for removal of toxic metals. Commercial activated carbons and synthetic ion-exchange resins have dominated the analytical scene so far, being applied to the separation/preconcentration of metals prior to their determination by FAAS, GFAAS, ICP-AES, and ICPMS (10). Activated carbon has proved to be an excellent collector for numerous metal ions and has been used for selective preconcentration of trace elements in a variety of samples $(16,17)$ ranging from geological, biological, environmental, high purity materials, seawater and ground water. Sorption and preconcentration of some transition metals, rare earths, platinum group metals on activated carbon prior to determination by ICPAES/ICP-MS have been reported (18 -21). Zr, Hf, Mo and $\mathrm{W}$ in waters and geological materials have been determined after sorption preconcentration on activated charcoal prior to their determination by ICP-AES and ICP-MS (22-24).

Polysaccharide-based natural materials are now emerging as a new group of sorbents. Chitin is one such bio-sorbent which is tough, protective, semitransparent, non-toxic and biodegradable (25). It is extracted from the hard shells of crustaceans, such as crab, lobster, and shrimp. Chitin is primarily a nitrogen-containing polysaccharide (N-acetyl-D-glucos-2-amine) which is insoluble in water and alkali but soluble in strong mineral acids. It forms complexes with transition metal ions. Chitin also finds application in many fields such as agriculture, food, biotechnology, textiles, polymers and water treatment. However, only a few analytical applications have been reported so far. Chitin has been used as the adsorbent column for preconcentration/separation of Fe as its 1,10 , phenanthroline complex in the presence of tetraphenyl borate as counter ion (26), Cr(VI) as its 1,5 , diphenylcarbazide complex in the presence of dodecyl sulphate (27) and Mo(VI)as molybdate in water samples (28) prior to their determination by spectrophotometry. Elsewhere, chitin has been used for preconcentration/separation of rare earth elements and platinum group elements $(29,30,31)$.

A survey of the literature as cited above shows that there are no studies published on preconcentration/ separation of $\mathrm{Nb}$ and $\mathrm{Ta}$ in geological materials using activated carbon and chitin as solid phase sorbents for their determination by ICP-AES or ICP-MS. The objective of this work was to develop a method for determining $\mathrm{Nb}$ and $\mathrm{Ta}$ at trace levels in different types of geological samples with preconcentration/ separation using solid phase sorbents, namely, activated carbon and chitin. The authors are reporting for the first time the preconcentration/separation of $\mathrm{Nb}$ and $\mathrm{Ta}$ by solid phase extraction in general and on activated carbon/chitin in particular.

\section{EXPERIMENTAL}

\section{Instrumentation}

An ICP-AES Model Ultima 2 (Jobin-Yvon, France) was used for the determination of $\mathrm{Nb}$ and $\mathrm{Ta}$. The instrumental parameters are listed in Table I.

\section{Reagents and Standards}

Activated carbon (AR grade, phosphorus-free) was procured from S.D.Finechem.Ltd, Mumbai, India. It was purified further by boiling with $1.2 \mathrm{M} \mathrm{HCl}$ to remove trace impurities. The carbon after boiling with $\mathrm{HCl}$ was filtered, the carbon washed repeatedly with distilled water, dried in a hot air oven at $50^{\circ} \mathrm{C}$ for one hour and stored in air-tight bottles for further use. Chitin obtained as flakes (from Loba Chemie Ltd., Mumbai, India) was finely powdered (200 mesh) in a shatter box, cleaned repeatedly by soaking in quartz doubledistilled water and decanting to remove impurities. The cleaned chitin was finally dried in a hot air oven at $100{ }^{\circ} \mathrm{C}$ for one hour and stored in air-tight bottles for further use. All reagents used were of analytical grade.

Niobium pentoxide and tantalum pentoxide (SpecPure $\left.{ }^{\circledR}\right)$ were obtained from Fluka AG, Buchs, SG (Switzerland). Niobium and tantalum standards $(250 \mu \mathrm{g} / \mathrm{mL}$ of oxides) were prepared by fusing 
$25 \mathrm{mg}$ each of niobium and tantalum pentoxide with $8 \mathrm{~g}$ of $\mathrm{KHSO}_{4}$ to a red hot melt at $700{ }^{\circ} \mathrm{C}$ for 30-45 minutes in a silica crucible. The melt after cooling to room temperature was dissolved in $100 \mathrm{~mL}$ of 3\% citric acid solution. Working standards were prepared by successive dilutions.

\section{Recommended Procedure for Sample Dissolution}

In neutral and acidic solutions, niobium and tantalum undergo hydrolysis. Tartaric acid, oxalic acid, citric acid, hydrofluoric acid or a mixture of hydrogen peroxidesulphuric acid are used to prevent hydrolysis and keep them in solution. For $\mathrm{Nb}-\mathrm{Ta}$ determination in geological samples, typically $0.5 \mathrm{~g}$ of the sample was accurately weighed in a Pt crucible. Silica in the samples was removed by volatilization as $\mathrm{SiF}_{4}$ by fuming with $5 \mathrm{~mL}$ of $40 \% \mathrm{HF}$ and $2 \mathrm{~mL}$ of $18 \mathrm{~N}$ sulphuric acid on a sand bath. The dried residue was fused with potassium bisulphate to a red hot melt, followed by dissolution of the fused melt in sulphuric/citric/tartaric acid solution. Since, citrate/tartrate/ oxalate interferes in the sorption step, 3\% (v/v) of $36 \mathrm{~N}$ sulphuric acid containing 1-2 $\mathrm{mL}$ of $30 \%(\mathrm{w} / \mathrm{v})$ hydrogen peroxide mixture was preferred for dissolving the material obtained after fusion.

\section{Recommended Procedure for Preconcentration by Solid Phase Extraction on Activated Carbon/Chitin}

To an appropriate aliquot of the sample solution taken in a $250 \mathrm{~mL}$ beaker, about $5 \mathrm{~mL}$ of $1 \%$ ascorbic acid was added, and the volume made up to $100 \mathrm{~mL}$. Then the $\mathrm{pH}$ of the solution was adjusted to 3 , and $0.5 \mathrm{~g}$ activated carbon/chitin was added, then the solution was allowed to stand for one hour with intermittent stirring. The solution was then filtered using Whatman 540 grade paper. The filter paper with carbon/chitin was dried thoroughly, taken in a Pt dish, and ignited at $650{ }^{\circ} \mathrm{C}$ for one hour. The residue obtained was dissolved in a mixture of $2 \mathrm{~mL}$ of $40 \% \mathrm{HF}$ and $0.5 \mathrm{~mL}$ of $18 \mathrm{~N}$ sulphuric acid on a water bath and evaporated to near

TABLE I

ICP-AES Operating Conditions and Instrumental Parameters (JY- Model ULTIMA-2)

$\begin{array}{ll}\text { Mounting } & \text { Czerny-Turner } \\ \text { Focal length } & 1 \mathrm{~m} \\ \text { Grating } & 4320 \text { grooves } / \mathrm{mm} \\ & \text { and } 2400 \text { grooves } / \mathrm{mm} \\ \text { Order of measurement } & 1 \mathrm{st} \\ \text { 1st order resolution } & 0.005 \\ \text { Type of generator } & \text { Solid state } \\ \text { Observation } & \text { Radial view } \\ \text { Frequency of generator } & 40.68 \mathrm{Mhz} \\ \text { Power } & 1000 \mathrm{~W} \\ \text { Plasma gas flow rate } & 12 \mathrm{~L} / \mathrm{min} \\ \text { Sheath gas flow rate } & 0.2 \mathrm{~L} / \mathrm{min} \\ \text { Nebuliser gas flow rate } & 0.8 \mathrm{~L} / \mathrm{min} \\ \text { Nebuliser type } & \text { Meinhard } \\ \text { Type of spray chamber } & \text { Cyclonic } \\ \text { Injector tube diameter } & 1.8 \mathrm{~mm}, \text { Alumina }\end{array}$

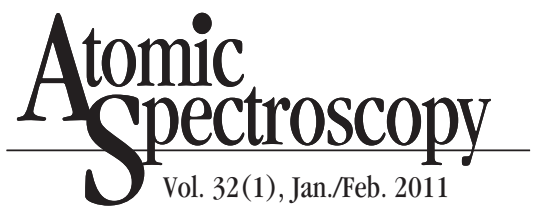

dryness. It was evaporated twice again to near dryness with few $\mathrm{mL}$ of distilled water. Finally, it was dissolved in $2 \mathrm{~mL}$ of $1 \%$ citric acid solution, made up to $10 \mathrm{~mL}$ volume and $\mathrm{Nb}$-Ta determined by ICP-AES.

\section{RESULTS AND DISCUSSION}

Selection of Emission Lines for the Determination of $\mathrm{Nb}$ and $\mathrm{Ta}$ by ICP-AES

Detailed investigations on the interference of other concomitant elements on $\mathrm{Nb}$ and $\mathrm{Ta}$ emission lines have been already been carried out by other workers and results published (14). The most sensitive emission lines of niobium are $309.418 \mathrm{~nm}, 316.340 \mathrm{~nm}$, and $313.079 \mathrm{~nm}$; those of tantalum are $240.065 \mathrm{~nm}, 226.230 \mathrm{~nm}$, and $268.517 \mathrm{~nm}$. The present method involves a separation step with solid phase extraction on a sorbent and, hence, very low concentrations of matrix ions are present in the final solution along with $\mathrm{Nb}$ and Ta. Further, the instrument used in the present study has a very high resolution of $0.005 \mathrm{~nm}$. Therefore, no interferences were observed by the authors from the residual matrix on both the $\mathrm{Nb}$ $309.418 \mathrm{~nm}$ and Ta $240.063 \mathrm{~nm}$ line (see Figures 1 and 2) and hence those lines were selected for this study.

\section{Optimization of Experimental Parameters for Quantitative Sorption}

The effects of several experimental parameters (such as $\mathrm{pH}$, weight of carbon/chitin, initial metal ion concentration, sample volume) on the sorption of $\mathrm{Nb}$ and Ta on both activated carbon and chitin were first studied. Since chitin is a bio-material, high acid concentrations (especially of nitric acid) degraded chitin which may affect its surface properties. 


\section{Effect of pH}

Double distilled water $(100 \mathrm{~mL})$ was spiked with $50 \mu \mathrm{g}$ of $\mathrm{Nb}$ and $\mathrm{Ta}$ (both elements taken together) and the $\mathrm{pH}$ was adjusted to values ranging from 1 to 6 . After adding $0.5 \mathrm{~g}$ of activated carbon, the solutions were allowed to stand for six hours with intermittent stirring. The amount of sorption at different $\mathrm{pH}$ values was determined from the residual $\mathrm{Nb} / \mathrm{Ta}$ concentrations in the filtrate, and the results obtained are given in Figure 3. Quantitative adsorption was observed from $\mathrm{pH}$ 2 to 6 for both $\mathrm{Nb}$ and Ta. Hence, the $\mathrm{pH}$ of 3 was preferred as optimum for quantitative sorption for $\mathrm{Nb}$ and Ta. Similar experiments were carried out using $0.5 \mathrm{~g}$ of chitin and the results obtained are given in Figure 4. Quantitative adsorption was observed only from $\mathrm{pH} 2$ to 4 for both $\mathrm{Nb}$ and $\mathrm{Ta}$.
Hence, $\mathrm{pH} 3$ was preferred as optimum for the quantitative sorption of $\mathrm{Nb}$ and $\mathrm{Ta}$ on chitin also.

\section{Effect of Sample Volume}

Different sample volumes ranging from $100 \mathrm{~mL}$ to $1000 \mathrm{~mL}$ of double distilled water were spiked with $50 \mu \mathrm{g}$ of $\mathrm{Nb}$ and $\mathrm{Ta}$ (both elements taken together) and the $\mathrm{pH}$ was adjusted to 3. After adding
$0.5 \mathrm{~g}$ of carbon, the solutions were allowed to stand for six hours with intermittent stirring and the amount of sorption was determined for the different sample volumes. The results obtained are given in Table II. It was observed that sorption was quantitative even up to a sample volume of $1000 \mathrm{~mL}$ for both elements. A maximum enrichment factor of 200 is feasible by the pre-

TABLE II

Effect of Sample Volume

\begin{tabular}{crrrr}
\hline Sample & \% Sorption on Carbon & \multicolumn{2}{c}{ \% Sorption on Chitin } \\
Volume & $\mathrm{Nb}$ & $\mathrm{Ta}$ & $\mathrm{Nb}$ & $\mathrm{Ta}$ \\
\hline $100 \mathrm{~mL}$ & $>98$ & $>98$ & $>98$ & $>98$ \\
$200 \mathrm{~mL}$ &, &, &, &, \\
$400 \mathrm{~mL}$ &, &, &, &, \\
$500 \mathrm{~mL}$ &, &, &, &, \\
$1 \mathrm{~L}$ & 98 & 98 & 98 & 98 \\
\hline
\end{tabular}

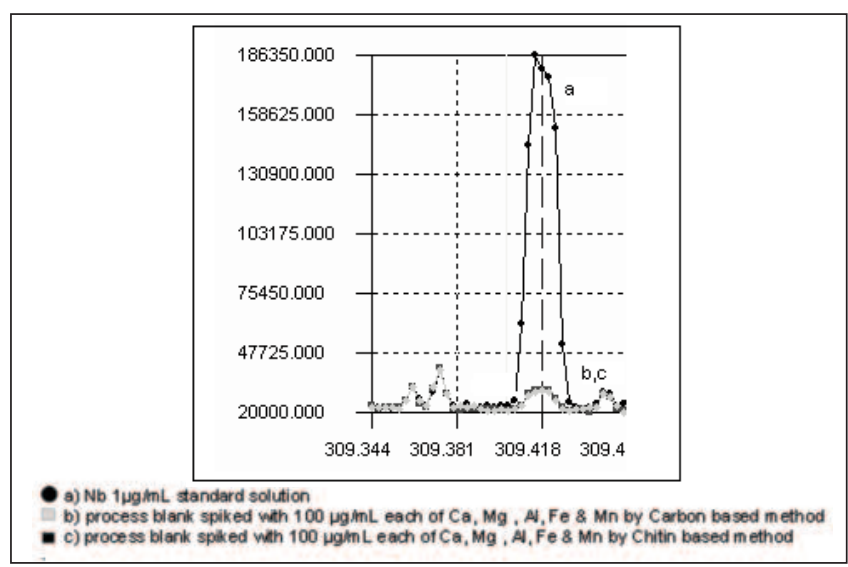

Fig. 1. Spectral profile of $\mathrm{Nb} 309.41 \mathrm{~nm}$ line.

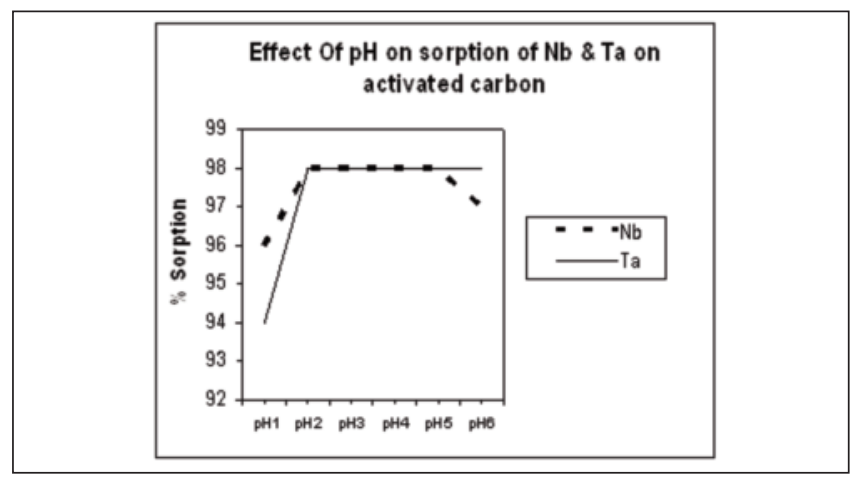

Fig. 3. Effect of $\mathrm{pH}$ on sorption of $\mathrm{Nb}$ and Ta on activated carbon.

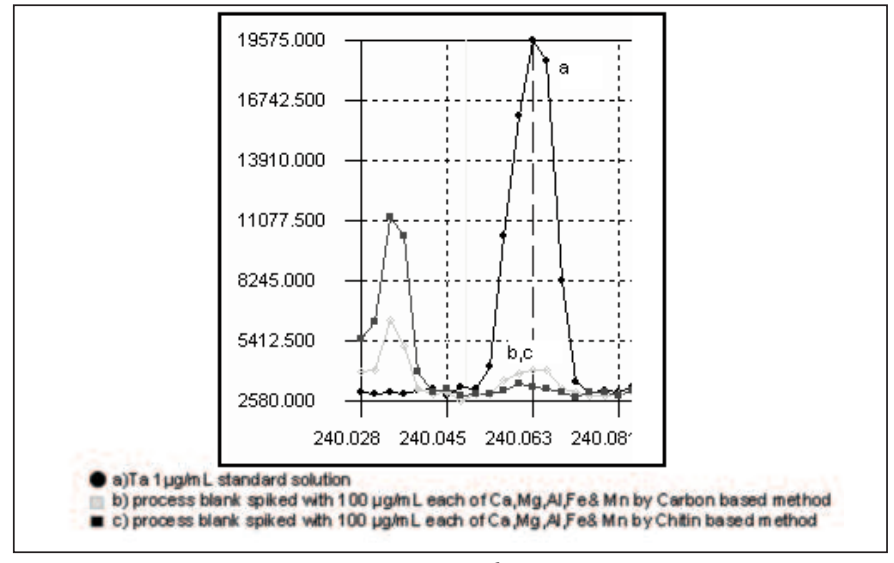

Fig. 2. Spectral profile of Ta $240.06 \mathrm{~nm}$ line.

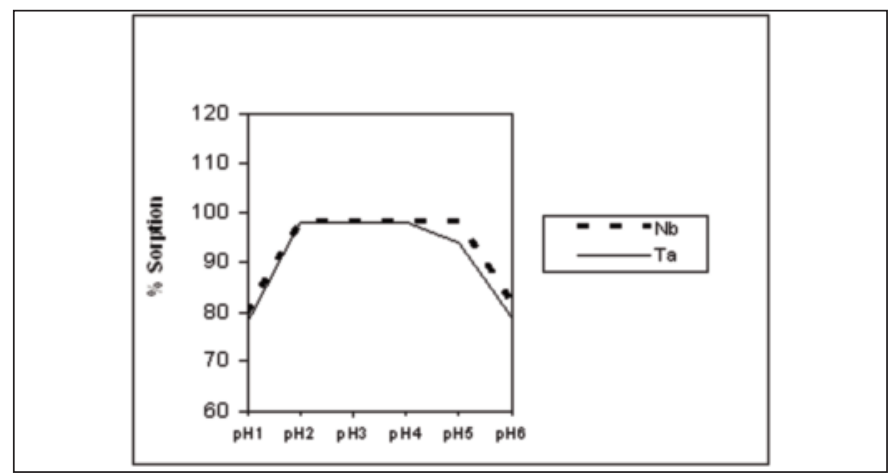

FIg. 4. Effect of pH on sorption of $\mathrm{Nb}$ and Ta on Chitin. 
sent preconcentration method for applications with aqueous samples (1000 $\mathrm{mL}$ initial volume to $5 \mathrm{~mL}$ final volume). Similar experiments were carried out separately using $0.5 \mathrm{~g}$ chitin. The results obtained are given in Table II. It was observed that sorption was quantitative up to a sample volume of $1000 \mathrm{~mL}$ for both elements and an enrichment factor of 200 is feasible by the present method using chitin also.

\section{Effect of Amount of Carbon and Chitin}

Varying amounts of carbon ranging from $25 \mathrm{mg}$ to $1000 \mathrm{mg}$ were added to $100 \mathrm{~mL}$ of double distilled water spiked with $50 \mu \mathrm{g}$ of $\mathrm{Nb}$ and $\mathrm{Ta}$ (both elements taken together) maintained at $\mathrm{pH} 3$. The solutions were allowed to stand for six hours with intermittent stirring and the amount of sorption was determined. The results obtained are given in Table III. It was observed that quantitative adsorption of $\mathrm{Nb}-\mathrm{Ta}$ occurred even with $100 \mathrm{mg}$ of carbon. However, $500 \mathrm{mg}$ carbon was taken as optimum for real samples. The results obtained on chitin are given in Table III. It was observed that quantitative adsorption of $\mathrm{Nb}$ Ta taken occurred with $100 \mathrm{mg}$ of chitin and $500 \mathrm{mg}$ chitin was deemed optimum for real samples.

TABLE III

Effect of Amount of Sorbent

\begin{tabular}{|c|c|c|c|c|}
\hline \multirow[t]{2}{*}{$\begin{array}{l}\text { Sorbent } \\
\text { (mg) }\end{array}$} & \multicolumn{2}{|c|}{$\begin{array}{l}\% \text { Sorption } \\
\text { on Cabron }\end{array}$} & \multicolumn{2}{|c|}{$\begin{array}{l}\% \text { Sorption } \\
\text { on Chitin }\end{array}$} \\
\hline & $\mathrm{Nb}$ & $\mathrm{Ta}$ & $\mathrm{Nb}$ & $\mathrm{Ta}$ \\
\hline 25 & 85 & 85 & 84 & 76 \\
\hline 50 & 90 & 90 & 94 & 92 \\
\hline 100 & $>98$ & $>98$ & 98 & 95 \\
\hline 200 & $>98$ & $>98$ & $>98$ & $>98$ \\
\hline 300 & $>98$ & $>98$ & $>98$ & $>98$ \\
\hline 500 & $>98$ & $>98$ & $>98$ & $>98$ \\
\hline 1000 & $>98$ & $>98$ & $>98$ & $>98$ \\
\hline
\end{tabular}

\section{Effect of Contact Time}

Carbon $(0.5 \mathrm{~g})$ was added to $100 \mathrm{~mL}$ of double distilled water spiked with $50 \mu \mathrm{g}$ of $\mathrm{Nb}$ and $\mathrm{Ta}$ (both elements taken together) maintained at $\mathrm{pH} 3$ and allowed to stand for different contact times ranging from 15 minutes to six hours, with intermittent stirring. The amount of sorption was determined and it was observed from the results obtained (see Table IV) that adsorption is quantitative in $15 \mathrm{~min}$ utes for both $\mathrm{Nb}$ and $\mathrm{Ta}$. Hence, contact time of one hour was deemed optimum for real samples. The above experiments were repeated with chitin also and it was observed from the results obtained (Table IV) that adsorption is quantitative in 30 minutes for both $\mathrm{Nb}$ and $\mathrm{Ta}$. Hence, contact time of two hours was deemed optimum for real samples. It was observed that sorption on carbon was a much faster process than on chitin and becomes quantitative within 15 minutes.

\section{Effect of Initial Metal Ion Concentration}

Double distilled water $(100 \mathrm{~mL})$ was spiked with different amounts of $\mathrm{Nb}$ and Ta ranging from $2 \mu \mathrm{g}$ to $500 \mu \mathrm{g}$ (both elements taken separately), the $\mathrm{pH}$ adjusted to 3 , and $0.5 \mathrm{~g}$ of carbon added; then the

TABLE IV

Effect of Contact Time

\begin{tabular}{crrrrr}
\hline \multirow{2}{*}{$\begin{array}{c}\text { Contact } \\
\text { Time }\end{array}$} & \multicolumn{2}{c}{ \% Sorption } & \multicolumn{2}{c}{ \% Sorption } \\
& On Carbon & \multicolumn{2}{c}{ on Chitin } \\
& Nb & Ta & Nb & Ta \\
\hline 15 min. & $>98$ & $>98$ & 98 & 95 \\
30 min. & $>98$ & $>98$ & $>98$ & $>98$ \\
1 hour & $>98$ & $>98$ & $>98$ & $>98$ \\
2 hours &, &,, &, &, \\
3 hours &, &, &, &, \\
4 hours &, &,, &, &,$"$ \\
\hline
\end{tabular}

solutions were allowed to stand for six hours with intermittent stirring. The amount of sorption was determined. From the results obtained (Table V) it was observed that $0.5 \mathrm{~g}$ of carbon was sufficient for quantitative adsorption of metals up to a maximum of $200 \mu \mathrm{g}$ for both elements. The results of similar experiments carried out separately using chitin (Table V) showed that $0.5 \mathrm{~g}$ of chitin was sufficient for quantitative adsorption of the metals up to a maximum of $100 \mu \mathrm{g}$ for both elements.

\section{Desorption and Recovery of $\mathrm{Nb}$ and Ta from Carbon and Chitin}

\section{(a) Leaching with mineral acids}

$\mathrm{Nb}$ and $\mathrm{Ta}$ do not form simple soluble compounds in aqueous solutions. In neutral and acid solutions, they are hydrolyzed and, hence, there is no option of recovering $\mathrm{Nb}$-Ta quantitatively in soluble form by leaching with HCl. However, some studies were carried out with other reagents. An amount of $100 \mathrm{~mL}$ of distilled water was spiked with $50 \mu \mathrm{g}$ of $\mathrm{Nb}-\mathrm{Ta}$, the $\mathrm{pH}$ adjusted to 3 , and $0.5 \mathrm{~g}$ carbon was added; then the solutions were allowed to stand for one hour. The solutions were filtered, the filtrate discarded and the carbon transferred back into the beaker along with $25 \mathrm{~mL}$ of desorbing

TABLE V

Effect of Initial Metal Ion Concentration

\begin{tabular}{lrrrr}
\hline Metal & \multicolumn{2}{c}{ \% Sorption } & \multicolumn{2}{c}{ \% Sorption } \\
Ion & \multicolumn{2}{c}{ on Carbon } & \multicolumn{2}{c}{ on Chitin } \\
(ug) & $\mathrm{Nb}$ & $\mathrm{Ta}$ & $\mathrm{Nb}$ & $\mathrm{Ta}$ \\
\hline 2 & $>98$ & $>98$ & $>98$ & $>98$ \\
10 & $>98$ & $>98$ & $>98$ & $>98$ \\
50 & $>98$ & $>98$ & $>98$ & $>98$ \\
100 & $>98$ & $>98$ & $>98$ & $>98$ \\
200 & 98 & 98 & 87 & 88 \\
500 & $<75$ & $<75$ & $<75$ & $<75$ \\
\hline
\end{tabular}


reagents and leached for two hours on a hot plate. The solutions were filtered and $\mathrm{Nb}$ and $\mathrm{Ta}$ in the filtrate were determined by ICP-AES. The desorbing agents tried were $10 \%$ nitric acid, a mixture of $10 \%$ nitric acid, 20\% hydrogen peroxide, and $1 \%$ citric acid. The results obtained are given in Table VI. There is total loss of tantalum but niobium could be recovered up to $32 \%$ with nitric acid. Citric acid was also not effective in leaching $\mathrm{Nb}-\mathrm{Ta}$ from carbon. Similar leaching studies were carried out with chitin as well and the results obtained are given in Table VI. Niobium and tantalum could be recovered up to $22 \%$ with nitric acid. Citric acid was not effective in leaching $\mathrm{Nb}$-Ta from chitin also.

\section{(b) Ignition method of recovery}

Since niobium and tantalum hydrolyze and could not be recovered with mineral acids, the feasibility of the ignition method for recovering the analytes was studied. After adsorption as per optimized conditions, the solution was filtered. The filter paper with carbon was transferred to a $\mathrm{Pt}$ dish, dried thoroughly, ignited at $650^{\circ} \mathrm{C}$ for one hour; Different dissolution reagents were tried to recover $\mathrm{Nb}$-Ta in soluble form from the carbon residue obtained after ignition. The residue was dissolved in different combination of the following acids: hydrofluoric acid, nitric acid, sulphuric acid and citric acid, and the recoveries determined. The results obtained are given in Table VII. Quantitative recovery was obtained using the combination of
HF, sulphuric acid and citric acid as follows: The residue obtained after ignition was dissolved in $2-3 \mathrm{~mL}$ of $40 \% \mathrm{HF}$ and $0.5 \mathrm{~mL}$ of $18 \mathrm{~N}$ sulphuric acid and evaporated to near dryness on a water bath. It was evaporated twice again to near dryness with a few $\mathrm{mL}$ of distilled water. Finally, it was dissolved in $2 \mathrm{~mL}$ of $1 \%$ citric acid solution, made up to $10 \mathrm{~mL}$ and $\mathrm{Nb}$-Ta determined by ICP-AES. The above experiments when carried out with chitin yielding similar results as on carbon. It was observed that the hydrolyzing tendency of these ions can lead to significant losses during the desorption step, especially while recovering higher amounts of $\mathrm{Nb}$ and $\mathrm{Ta}$, and utmost care is to be taken. Tantalum was found more susceptible to this problem than $\mathrm{Nb}$.

\section{Interference Studies}

The effect of various anions on the sorption process was studied and the results obtained are given in Table VIII. Amongst the anions, sulphate, chloride and phosphate showed no interference. Fluoride, citrate and the complexing agent EDTA exhibited some degree of interference, whereas oxalate inhibited sorption quite severely. The effect of other cations present in geological samples on adsorption was also studied. It was observed that Fe showed slight interference, but $\mathrm{Al}$ and $\mathrm{Mn}$ showed significant interference (Table IX). None of the trace elements $(\mathrm{Cu}, \mathrm{Co}, \mathrm{Ni}, \mathrm{Pb}, \mathrm{Zn}$, $\mathrm{Cd}, \mathrm{Cr}, \mathrm{V}$ ) showed any interference on sorption.

The results obtained on the effect of anions on sorption on chitin are also given in Table VIII. Sulphate and chloride did not interfere, but phosphate showed slight interference on Ta sorption. Fluoride interfered quite significantly, while complexing ions like EDTA and citrate interfered less severely. Similar to carbon, oxalate ion inhibited the sorption most severely. The effect of cations on sorption on chitin was also studied (Table IX). Amongst major ions, $\mathrm{Al}, \mathrm{Fe}$, and $\mathrm{Mn}$ interfered on sorption. However, it was observed that the interference from iron could be minimized with the addition of ascorbic acid for both carbon- as well as chitin-based methods. None of the trace cations showed any significant interference on sorption. Studies were also carried out to see whether interference on sorption would occur from the high levels of fusion flux and complexing acid used for sample dissolution which would invariably be present in the sample solution. For this, $100 \mathrm{~mL}$ of process blank solutions containing different levels of dissolved $\mathrm{KHSO}_{4}$ flux and acids were doped with 50 micrograms of $\mathrm{Nb}-\mathrm{Ta}$ and sorption was carried out at $\mathrm{pH} 3$ with $0.5 \mathrm{~g}$ activated carbon for one hour. The results obtained
TABLE VI Desorption Studies

\begin{tabular}{|c|c|c|c|c|}
\hline \multirow[t]{2}{*}{$\begin{array}{l}\text { Leachant } \\
\text { Used }\end{array}$} & \multicolumn{2}{|c|}{$\begin{array}{r}\% \text { Recovery } \\
\text { on Carbon }\end{array}$} & \multicolumn{2}{|c|}{$\begin{array}{l}\% \text { Recovery } \\
\text { on Chitin }\end{array}$} \\
\hline & $\mathrm{Nb}$ & $\mathrm{Ta}$ & $\mathrm{Nb}$ & $\mathrm{Ta}$ \\
\hline $10 \% \mathrm{HNO}_{3}$ & 32 & $<5$ & 22 & 14 \\
\hline $20 \% \mathrm{H}_{2} \mathrm{O}_{2}+10 \% \mathrm{HNO}_{3}$ & 32 & $<5$ & 23 & 15 \\
\hline 1\% Citric Acid & 20 & $<5$ & $<5$ & $<5$ \\
\hline $0.2 \%$ Citric Acid & $<5$ & $<5$ & $<5$ & $<5$ \\
\hline
\end{tabular}

TABLE VII Studies on Dissolution Procedures for Carbon/Chitin Residue

\begin{tabular}{lcccc}
\hline Dissolution & \multicolumn{2}{c}{ \% Recovery } & \multicolumn{2}{c}{ Recovery } \\
Reagents for & \multicolumn{2}{c}{ on Carbon } & \multicolumn{2}{c}{ on Chitin } \\
Recovery & $\mathrm{Nb}$ & $\mathrm{Ta}$ & $\mathrm{Nb}$ & $\mathrm{Ta}$ \\
\hline $\mathrm{HF} / \mathrm{HNO}_{3}$ & 20 & 10 & - & - \\
$\mathrm{HF} / \mathrm{H}_{2} \mathrm{SO}_{4}$ & 50 & 40 & - & - \\
$\mathrm{HF} / \mathrm{H}_{2} \mathrm{SO}_{4} / \mathrm{HNO}_{3}$ & 75 & 55 & - & - \\
$\mathrm{HF} / \mathrm{HNO}_{3} / \mathrm{H}_{2} \mathrm{O}_{2}$ & 60 & 5 & - & - \\
$\mathrm{HF} / 0.25 \% \mathrm{Citric}_{2}$ Acid & 85 & 50 & - & - \\
$\mathrm{HF} / \mathrm{H}_{2} \mathrm{SO}_{4} / 0.1-0.2 \%$ Citric Acid & $>95$ & $>95$ & $>95$ & $>95$ \\
\hline
\end{tabular}


are given in Table X. From the results obtained it was observed that sulphuric acid- $\mathrm{H}_{2} \mathrm{O}_{2}$ mixture is preferable for dissolution of the melt obtained after fusion with $4 \mathrm{~g}$ $\mathrm{KHSO}_{4}$ since it causes no interference during the sorption step.

\section{Choice of Medium for Sorption}

Tartaric acid, citric acid, and oxalic acid are used as media for stabilization of niobate and tantalate solutions. Among the three, citric acid solutions have longer shelf life and stability. Hence, citric acid was used in the present investigations as medium for stabilizing niobate and tantalate solutions. Though 3\% citric acid was chosen as the medium for preparing the standard stock solution, very minor quantities of the same were present in the working standards after successive dilution and, hence, the medium for sorption studies also contained negligible amounts of citric acid.

\section{Mechanisms of the Sorption Process}

Niobium and tantalum do not form simple soluble compounds in aqueous solutions. In neutral and acid solutions, simple compounds of $\mathrm{Nb}$ and $\mathrm{Ta}$ are hydrolyzed with formation of hydrophilic colloidal systems. Literature data on the ionic states of $\mathrm{Nb}$ and $\mathrm{Ta}$ are very scarce $(2,3,6,37)$. Niobium and tantalum complexes are stable in aqueous solutions only in the presence of high concentrations of ligands like citrate, tartrate, or oxalate. Otherwise, they readily hydrolyze with the formation of white gelatinous precipitates of $\mathrm{Nb}$ and Ta hydroxides (niobic and tantalic acids) of the composition $\mathrm{M}_{2} \mathrm{O}_{5} \cdot \mathrm{X} \cdot \mathrm{H}_{2} \mathrm{O}$ or $\left(\mathrm{M}_{2} \mathrm{O}_{5} \cdot \mathrm{x} \cdot \mathrm{H}_{2} \mathrm{O}\right) \mathrm{n}$. These are insoluble in water but are readily peptized.

TABLE VIII

Effect of Common Anions

\begin{tabular}{lrrrr}
\hline Anion Added & \multicolumn{2}{c}{ \% Sorption } & \multicolumn{2}{c}{ \% Sorption } \\
& \multicolumn{2}{c}{ on Carbon } & \multicolumn{2}{c}{ on Chitin } \\
& Nb & Ta & Nb & Ta \\
\hline 1000 ppm Chloride & $>95$ & $>95$ & $>95$ & $>95$ \\
500 ppm Sulphate & $>95$ & $>95$ & $>95$ & $>95$ \\
100 ppm Phosphate & $>95$ & $>95$ & $>95$ & 90 \\
100 ppm Fluoride & 90 & 90 & 90 & 90 \\
1\% EDTA & 90 & 85 & 95 & 70 \\
0.2\% Citrate & 95 & 80 & 90 & 70 \\
0.5\% Citrate & 95 & 75 & 90 & 75 \\
1\% Citrate & 90 & 75 & 85 & 70 \\
1\% Tartrate & 90 & 75 & 85 & 70 \\
1\% Oxalate & 40 & 40 & 35 & 35 \\
\hline
\end{tabular}

TABLE $X$

Studies on Recovery of $\mathrm{Nb} / \mathrm{Ta}$ in Presence of Complexants

\begin{tabular}{|c|c|c|c|c|c|c|}
\hline Matrix & $\begin{array}{c}\text { Nb } \\
\text { Spiked } \\
(\mu \mathrm{g})\end{array}$ & $\begin{array}{c}\mathrm{Nb} \\
\text { Obtained } \\
(\mu \mathrm{g})\end{array}$ & $\%$ Recovery & $\begin{array}{c}\text { Ta } \\
\text { Spiked } \\
(\mu g)\end{array}$ & $\begin{array}{c}\mathrm{Ta} \\
\text { Obtained } \\
(\mu \mathrm{g})\end{array}$ & \% Recovery \\
\hline $8 \mathrm{~g} \mathrm{KHSO}_{4}+3 \% \mathrm{CA}$ & 50 & 22 & 44 & 50 & 20 & 40 \\
\hline $4 \mathrm{~g} \mathrm{KHSO}_{4}+3 \% \mathrm{CA}$ & 50 & 22.5 & 45 & 50 & 20 & 40 \\
\hline $4 \mathrm{~g} \mathrm{KHSO}_{4}+1 \% \mathrm{CA}$ & 50 & 42.5 & 85 & 50 & 40 & 80 \\
\hline $4 \mathrm{~g} \mathrm{KHSO}_{4}+3 \% \mathrm{H}_{2} \mathrm{SO}_{4}$ Acid $-0.5 \mathrm{~mL}$ of $\mathrm{H}_{2} \mathrm{O}_{2}$ & 50 & 47.5 & 95 & 50 & 45 & 90 \\
\hline
\end{tabular}


anion in solution and (b)

coordinate covalent bonding between lone pair electrons of nitrogen and/or oxygen and metals in solution. The $\mathrm{pH}$ is the dominating parameter in determining the adsorption mechanism. On chitin, molybdenum and tungsten have been reported to be retained strongly from $\mathrm{pH} 3$ to 4 , whereas $\mathrm{Zr}$ and $\mathrm{Hf}$ were retained from $\mathrm{pH} 2$ to 5 (31). Quantitative sorption of niobium and tantalum was observed in the $\mathrm{pH}$ range of $2-4$ on chitin in the present investigations. Hence, it is probably the anionic ortho-niobate and tantalate species and also their iso-poly ions which adsorb on chitin. This is supported by the fact that chitin has been reported to act as a collector for anionic species in solution under weakly acidic conditions $(35,36)$. So, it is probably the electrostatic interaction between chitin and the anions which contributes to their sorption. With increasing $\mathrm{pH}$, the extent of protonation of chitin decreases and hence there is a decrease in the electrostatic interaction with anions as well and other factors become dominating. This could probably be the reason for the fall in sorption beyond $\mathrm{pH} 4$ which could also probably be attributed to higher solubility of the niobate and tantalate species in the aqueous phase under such $\mathrm{pH}$ conditions.

\section{Procedural Blank}

Procedural blanks were run concurrently along with the samples in order to assess any contribution arising from carbon, chitin and other reagents used. The values obtained were within experimentally found determination limits for all four elements by ICP-AES.

TABLE XI

Determination of $\mathrm{Nb}$ in Standard Reference Materials

\begin{tabular}{|c|c|c|c|c|c|c|}
\hline $\begin{array}{l}\text { Sample } \\
\text { No. }\end{array}$ & $\begin{array}{l}\text { Sample } \\
\text { Type } \\
\\
\\
\mathrm{U}\end{array}$ & $\begin{array}{c}\mathrm{Nb} \\
\left(\mu \mathrm{g} \mathrm{g}^{-1}\right) \\
\text { by Present } \\
\text { Method } \\
\text { Using Carbon }\end{array}$ & $\% \mathrm{RSD}$ & $\begin{array}{c}\mathrm{Nb} \\
\left(\mu \mathrm{g} \mathrm{g}^{-1}\right) \\
\text { by Present } \\
\text { Method } \\
\text { Using Chitin }\end{array}$ & $\% \mathrm{RSD}$ & $\begin{array}{c}\mathrm{Nb} \\
\left(\mu \mathrm{g} \mathrm{g}^{-1}\right) \\
\text { Recommended } \\
\text { Value } \\
(38)\end{array}$ \\
\hline G-2 & Granite & 12.8 & 2.2 & 12.4 & 3.3 & 12 \\
\hline BHVO-1 & Basalt & 21.0 & 1.4 & 19.8 & 2.8 & 19 \\
\hline SDC-1 & mica schist & 17.8 & 1.6 & 17.6 & 3.2 & 18 \\
\hline SDO-1 & ohio shale & 11.7 & 2.1 & 11.9 & 2.1 & 11.4 \\
\hline SO-1 & Soil & 10.8 & 3.8 & 10.6 & 3.8 & 11.7 \\
\hline $\mathrm{SO}-2$ & Soil & 20.8 & 1.0 & 21.2 & 2.2 & 22 \\
\hline W-2 & Diabase & 8.4 & 4.5 & 8.2 & 4.6 & 7.9 \\
\hline JG-2 & Granite & 14.2 & 2.5 & 14.4 & 2.5 & 15 \\
\hline $\begin{array}{l}\text { SARM-1 } \\
\text { (NIM-G) }\end{array}$ & Granite & 51 & 1.8 & 52 & 1.6 & 54 \\
\hline
\end{tabular}

TABLE XII

Determination of $\mathrm{Ta}$ in Standard Reference Materials

\begin{tabular}{|c|c|c|c|c|c|c|}
\hline $\begin{array}{l}\text { Sample } \\
\text { No. }\end{array}$ & $\begin{array}{l}\text { Sample } \\
\text { Type }\end{array}$ & $\begin{array}{c}\mathrm{Ta} \\
\left(\mu \mathrm{g} \mathrm{g}^{-1}\right) \\
\text { by Present } \\
\text { Method } \\
\text { Using Carbon }\end{array}$ & $\%$ RSD & $\begin{array}{c}\mathrm{Ta} \\
\left(\mu \mathrm{g} \mathrm{g}^{-1}\right) \\
\text { by Present } \\
\text { Method } \\
\text { Using Chitin }\end{array}$ & $\% \mathrm{RSD}$ & $\begin{array}{c}\text { Ta } \\
\left(\mu \mathrm{g} \mathrm{g}^{-1}\right) \\
\text { Recommended } \\
\text { Value } \\
(38)\end{array}$ \\
\hline $\begin{array}{l}\text { SARM-1 } \\
\text { (NIM-G) }\end{array}$ & Granite & 5.2 & 5.8 & 5.1 & 6.0 & 4.5 \\
\hline
\end{tabular}


for sample decomposition followed by ICP-MS determination (10). Since samples containing significant amounts of Ta were unavailable, some quartzite samples were spiked with known amounts of Ta.

TABLE XIII

Determination of $\mathrm{Nb}$ in Geological Samples

\begin{tabular}{|c|c|c|c|c|c|c|}
\hline $\begin{array}{l}\text { Sample } \\
\text { No. }\end{array}$ & $\begin{array}{l}\text { Sample } \\
\text { Type }\end{array}$ & $\begin{array}{l}\mathrm{Nb} \\
\left(\mu \mathrm{g} \mathrm{g}^{-1}\right) \\
\text { by Present } \\
\text { Method } \\
\text { Jsing Carbon }\end{array}$ & $\%$ RSD & $\begin{array}{c}\mathrm{Nb} \\
\left(\mu \mathrm{g} \mathrm{g}^{-1}\right) \\
\text { by Present } \\
\text { Method } \\
\text { Using Chitin }\end{array}$ & $\%$ RSD & $\begin{array}{l}\mathrm{Nb} \\
\left(\mu \mathrm{g} \mathrm{g} \mathrm{g}^{-1}\right) \\
\text { Reported } \\
\text { Method } \\
\quad(10)\end{array}$ \\
\hline AMD-1B & $\begin{array}{l}1.5 \% \mathrm{Fe}_{2} \mathrm{O}_{3} \\
32 \% \mathrm{Al}_{2} \mathrm{O}_{3} \\
43 \% \mathrm{SiO}_{2} \\
3.2 \% \\
\mathrm{X}_{2} \mathrm{O}, 13.9 \% \mathrm{YO}\end{array}$ & 34 & 2.8 & 33 & 3.0 & 36 \\
\hline AMD-2B & $\begin{array}{l}5.5 \% \mathrm{Fe}_{2} \mathrm{O}_{3} \\
12 \% \mathrm{Al}_{2} \mathrm{O}_{3} \\
70 \% \mathrm{SiO}_{2} \\
5.1 \% \mathrm{X}_{2} \mathrm{O}, 3.0 \% \mathrm{YO}\end{array}$ & 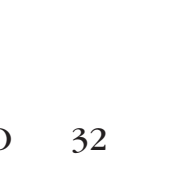 & 3.2 & 34 & 3.2 & 31 \\
\hline AMD-3B & $\begin{array}{l}4.8 \% \mathrm{Fe}_{2} \mathrm{O}_{3} \\
11 \% \mathrm{Al}_{2} \mathrm{O}_{3} \\
72 \% \mathrm{SiO}_{2} \\
4.2 \% \mathrm{X}_{2} \mathrm{O}, 5.5 \% \mathrm{YO}\end{array}$ & 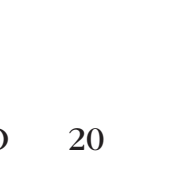 & 3.8 & 20 & 3.9 & 23 \\
\hline AMD-4B & $\begin{array}{l}2.2 \% \mathrm{Fe}_{2} \mathrm{O}_{3} \\
16 \% \mathrm{Al}_{2} \mathrm{O}_{3} \\
64 \% \mathrm{SiO}_{2}, \\
7.0 \% \mathrm{X}_{2} \mathrm{O}, 5.0 \% \mathrm{YO}\end{array}$ & 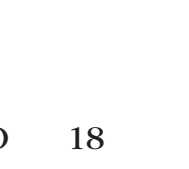 & 4.0 & 17 & 4.2 & 19 \\
\hline AMD-5B & $\begin{array}{l}1.8 \% \mathrm{Fe}_{2} \mathrm{O}_{3}, \\
13 \% \mathrm{Al}_{2} \mathrm{O}_{3}, \\
73 \% \mathrm{SiO}_{2}, \\
7.2 \% \mathrm{X}_{2} \mathrm{O}, 1.7 \% \mathrm{YO}\end{array}$ & 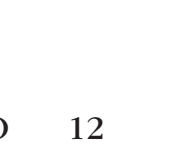 & 5.5 & 11.5 & 6.0 & 13 \\
\hline
\end{tabular}

TABLE XIV

Determination of Ta in Geological Samples

\begin{tabular}{|c|c|c|c|c|c|c|}
\hline \multirow{2}{*}{$\begin{array}{c}\text { Sample } \\
\text { No. }\end{array}$} & \multirow{2}{*}{$\begin{array}{l}\text { Sample } \\
\text { Type }\end{array}$} & \multirow{2}{*}{$\begin{array}{c}\mathrm{Ta} \\
(\mathrm{Spiked}) \\
(\mu \mathrm{g})\end{array}$} & \multicolumn{2}{|c|}{ By Carbon Method } & \multicolumn{2}{|c|}{ By Chitin Method } \\
\hline & & & $\begin{array}{c}\mathrm{Ta} \\
\text { (Obtained) } \\
(\mu \mathrm{g})\end{array}$ & $\begin{array}{c}\% \\
\text { Recovery }\end{array}$ & $\begin{array}{c}\text { Ta } \\
\text { (Obtained) } \\
(\mu \mathrm{g})\end{array}$ & $\begin{array}{c}\% \\
\text { Recovery }\end{array}$ \\
\hline AMD-1C & $\begin{array}{l}0.5 \% \mathrm{Fe}_{2} \mathrm{O}_{3}, \\
9 \% \mathrm{Al}_{2} \mathrm{O}_{3} \\
84 \% \mathrm{SiO}_{2} \\
3.2 \% \mathrm{X}_{2} \mathrm{O} \\
1.8 \% \mathrm{YO}\end{array}$ & 20 & 19.2 & 96 & 19.0 & 95 \\
\hline AMD-2C & $\begin{array}{l}4.0 \% \mathrm{Fe}_{2} \mathrm{O}_{3}, \\
4.5 \% \mathrm{Al}_{2} \mathrm{O}_{3}, \\
85 \% \mathrm{SiO}_{2}, \\
0.7 \% \mathrm{X}_{2} \mathrm{O}, \\
2.5 \% \mathrm{YO}\end{array}$ & 50 & 47.5 & 95 & 48 & 96 \\
\hline
\end{tabular}

\section{Atomic Apectroscopy \\ 1 Vol. 32(1), Jan./Feb. 2011}

The spiking procedure required a standard solution containing $10 \mu \mathrm{g} / \mathrm{mL}$ tantalum which was taken in a platinum crucible, dried under an Infra-red lamp, $0.5 \mathrm{~g}$ of the sample was weighed accurately, and the sample solution prepared as described above under the heading "Procedure for Sample Dissolution" and analyzed by the present method. The results obtained are given in Table XIV. The present method gave good recoveries.

\section{CONCLUSION}

The preconcentration method developed for niobium and tantalum is simple in methodology fbatch methods that can be applied in mobile geochemical vans stationed in field areas\}, rapid, economical, and eco-friendly as nontoxic/bio-compatible sorbents are used. Further, the preconcentration method developed gives accurate and precise results when applied to geological samples.

These methods can be interfaced with not only ICP-AES but also with ICP-MS and other instrumental analytical techniques which require separation from matrix components (for minimization of interferences) and low levels of total dissolved salts (TDS) in solution (to prevent clogging of instrument components like nebulizers, cones. etc.).

\section{ACKNOWLEDGMENT}

The authors thank Director, AMD, for his support and kind permission to carry out this work. The authors also thank Additional Director (R\&D) and Dr.K.Satyanaraya, Head, Chemistry Group, AMD. for their encouragement and support.

$\overline{\text { Received October 11, } 2010}$ 


\section{REFERENCES}

1. P.G. Jeffery, Chemical Methods of Rock Analysis, Pergamon Press, Oxford, UK, pp.483-490 (1970).

2. R.W. Moshier, Analytical Chemistry of Niobium and Tantalum, Pergamon Press, Oxford, UK, pp.1-16 (1964).

3. I.M. Gibalo, Analytical Chemistry of Niobium and Tantalum, Israel Program for Scientific Translations, Jerusalem, Israel (1968).

4. D.D. Sood, Nuclear Materials IANCAS Publications, Mumbai, India, pp.115-121(1996).

5. S. Weyer, C. Münker, M. Rehkämper, and K. Mezger, Chemical Geology, 187(3-4), 295 (2002).

6. I.M. Kolthoff, P.J. Elving, and E.B. Sandell, Treatise on Analytical Chemistry, Part.II, Volume 6, pp. 177-406, pp. 61-131, InterScience Publishers, New York (1961).

7. K.E. Jarvis, A.L. Gray, and R.S. Houk, HandBook of ICP-MS, Blackie, London \& Glasgow, U.K, 221 (1992).

8. G.E.M. Hall, J.C. Pelchat, and J. Loop, J. Anal. At. Spectrom.5, 339 (1990).

9. K.E. Jarvis, Chemical Geology 83, 89 (1990).

10. Z. Yu, P. Robinson, and P. McGoldrick, Geostand.Newsl, 25 (2-3), 199 (2001).

11. P. Roychowdhury, N.K. Roy and A.K. Das, Atomic Spectroscopy, 16,104 (1995).

12. G.E.M. Hall and J.C. Pelchat, Geostand. Newsl. 14(1), 197 (1990).

13. J. Yang and C. Pin, Anal. Chim. Acta 458(2), 375 (2002).

14. K. Satyanarayana and M.A. Nayeem, At. Spectrosc. 14(6), 180 (1993).

15. V. Camel, Spectrochim. Acta, Part B, 58, 1177 (2003).

16. B. Mikuła and B. Puzio, Talanta 71(1), 136 (2007).

17. K. Kiran, K. Suresh Kumar, K. Suvardhan, K. Janardhanam, and P. Chiranjeevi, J. of Hazardous Materials 147(1-2), 15 (2007).

18. G.E.M. Hall and J.C. Pelchat, J. Anal. At. Spectrom. 8, 1059 (1993).
19. B.N. Vanderborght and R.E. Van Grieken, Anal. Chem. 49(2), 311 (1977).

20. D.S.R. Murty and G. Chakrapani, J. Anal.At. Spectrom. 11, 815 (1996).

21. G. Chakrapani, D.S.R. Murty, P.L. Mohanta, and R.Rangaswamy, J. of Geochem. Exploration 63, 145 (1998).

22 .H.C. Dos Santos, M.G.A. Korn, and S.L.C. Ferreira, Anal. Chim. Acta 426(1), 79 (2001).

23.G.E.M. Hall, J.C. Pelchat, and K. Nimalasiri de Silva, Analyst 112( 5), 631 (1987).

24. G.E.M. Hall, C.J. Park, and J.C. Pelchat , J. Anal. At. Spectrom. 2, 189 (1987).

25. E. Khor, Current Opinion in Solid State and Materials Science 6( 4), 313 (2002).

26. S. Hoshi, M. Yamada, S. Inoue, and M. Matsubara, Talanta 36, 606 (1989).

27. S. Hoshi, H.Minamisawa, K. Sugawara, M. Uto, and K. Akatsuka, Talanta 47, 659 (1998).

28. S. Hoshi, K. Konuma, K. Sugawar, M. Uto, and K. Akatsuka, Talanta 44, 1473 (1997).

29. Anitha Mary Thomas, Ph.D, Thesis, Bangalore University, Bangalore, India (2002).

30. Anitha Mary Thomas and D.S.R.Murty, At. Spectrosc. 29(2), 69 (2008).

31. V.Padmasubashini and D.S.R.Murty, At. Spectrosc. 30(1), 32 (2009).

32. D.J. Hutchinson and A.A. Schilt, Anal. Chim. Acta 154, 159 (1983).

33. E. Piperaki, W. Berndt, and E. Jackwerth, Anal. Chim. Acta 100, 589 (1978).

34. V. Padmasubashini and D.S.R. Murty, Exploration and Research for Atomic Minerals 17, 180 (2009).

35. H. Minamisawa, N. Arai, and T. Okutani, Anal. Sci. 11, 961 (1995).

36. S. Hoshi, S. Kanagami, M. Uto, and M. Matsubara, Anal. Sci. 8, 103 (1992).
37. A.I. Busev, V.G. Tiptsova, and V.M. Ivanov, Analytical Chemistry of Rarer Elements, Mir Publishers, Moscow, Russia, 154, 224 (1981).

38. K. Govindaraju ( Editor-in-Chief), Geo-Standards NewsLetter, Special Issue, 18 (1994). 